\title{
Decolorization of two synthetic dyes using the purified laccase of Paraconiothyrium variabile immobilized on porous silica beads
}

Seyedeh-Shaghayegh Mirzadeh ${ }^{1,2,3}$, Seyed-Mostafa Khezri ${ }^{4}$, Shahla Rezaei ${ }^{1}$, Hamid Forootanfar ${ }^{5}$, Amir Hossein Mahvi ${ }^{2,6^{*}}$ and Mohammad Ali Faramarzi ${ }^{1^{*}}$

\begin{abstract}
Background: Decolorization of hazardous synthetic dyes using laccases in both free and immobilized form has gained attention during the last decades. The present study was designed to prepare immobilized laccase (purified from Paraconiothyrium variabile) on porous silica beads followed by evaluation of both free and immobilized laccases for decolorization of two synthetic dyes of Acid Blue 25 and Acid Orange 7. Effects of laccase concentration, $\mathrm{pH}$ and temperature alteration, and presence of 1-hydroxybenzotriazole (HBT) as laccase mediator on decolorization pattern were also studied. In addition, the kinetic parameters $\left(K_{m}\right.$ and $\left.V_{\max }\right)$ of the free and immobilized laccases for each synthetic dye were calculated.
\end{abstract}

Results: Immobilized laccase represented higher temperature and pH stability compare to free one. 39\% and 35\% of Acid Blue 25 and Acid Orange 7 was decolorized, respectively after 65 min incubation in presence of the free laccase. In the case of immobilized laccase decolorization percent was found to be 76\% and 64\% for Acid Blue 25 and Acid Orange 7, respectively at the same time. Increasing of laccase activity enhanced decolorization percent using free and immobilized laccases. Relative decolorization of both applied dyes was increased after treatment by laccase-HBT system. After nine cycles of decolorization by immobilized laccase, $26 \%$ and $31 \%$ of relative activity were lost in the case of Acid Blue 25 and Acid Orange 7, respectively.

Conclusions: To sum up, the present investigation introduced the immobilized laccase of $P$. variabile on porous beads as an efficient biocatalyst for decolorization of synthetic dyes.

Keywords: Laccase, Immobilization, Decolorization, Synthetic dye, 1-hydroxybenzotriazole

\section{Introduction}

Discharge of a wide range of synthetic dyes produced and being increasingly used by different industries to ecosystems made this subject as a major environmental problem [1,2]. In aquatic ecosystems, entrance of dyes decreases the oxygen level due to reducing the amount of sunlight for photosynthetic organisms [3]. Some of these dyes are toxic and carcinogen in nature and found to be recalcitrant [4]. Time and cost consuming

\footnotetext{
* Correspondence: ahmahvi@yahoo.com; faramarz@tums.ac.ir

${ }^{2}$ Department of Environmental Health Engineering, School of Public Health; Center for Solid Waste Research; Institute of Public Health Research, Tehran University of Medical Sciences, Tehran, Iran

'Department of Pharmaceutical Biotechnology, Faculty of Pharmacy and

Biotechnology Research Center, Tehran University of Medical Sciences,

Tehran 14176 , Iran

Full list of author information is available at the end of the article
}

characteristic of physicochemical methods like coagulation, flocculation, adsorption, ion-exchange, oxidation and electrochemical methods applied for removal of synthetic dyes $[4,5]$ together with generating undesirable by-products prompts researchers to study on biological or enzymatic techniques for degradation of hazardous dyes $[6,7]$. Supplying much more eco-friendly process due to production of non-toxic metabolites, requiring mild conditions (temperature, pressure and $\mathrm{pH}$ ) and less water consumption in comparison with physicochemical techniques and being cost-competitive are some advantages of enzymatic methods for decolorization and removal of synthetic dyes $[1,3,5]$. 
Laccases (benzenediol: oxygen oxidoreductases, EC 1.10.3.2) are multi-copper oxidases produced mainly by fungal strains, specially white-rot fungi $[8,9]$. The ability of laccases for oxidation of a broad range of substrates like chlorinated phenol, polycyclic aromatic hydrocarbons (PAHs), benzenethiols and textile dyes in presence of molecular oxygen as co-substrate introduced this biotechnologically important enzyme as the first choice for xenobiotic removal investigations $[8,10]$. However, low stability and low production yield are two main constraints for application of laccases in industrial processes $[11,12]$. Such mentioned problems could be overcome by development of immobilized laccases from different resources on solid supports which allow reusing of immobilized enzyme and may improve its stability [12,13]. Entrapment of enzyme in polymers, enzyme encapsulation in membranes, self-immobilization and covalent binding of enzymes to solid support are techniques used for fixation of enzymes [14] among which covalent biding supply more stable enzymes by increasing the rigidity of its structure and reducing protein unfolding [15]. During the recent years, wide range of supports like chitosan, chitosan/ poly(vinyl alcohol) composite nanofibrous membranes, magnetic mesoporous silica nanoparticles and mesostructured siliceous cellular foams have been used for development of immobilized laccases [14]. Mesoporous silica materials are one of the most applied matrices for immobilization of enzymes due to specific properties such as hydrothermal resistance, well order porous structure and high surface area [16].

In the present study, the purified laccase from a soil isolated ascomycete, $P$. variabile, was immobilized on the porous silica particles and applied for decolorization of two synthetic dyes of Acid Orange 7 and Acid Blue 25 compared to free enzyme. Furthermore, the influences of conditional parameters such as enzyme activity, temperature, and $\mathrm{pH}$ on decolorization were investigated. The kinetic parameters $\left(K_{\mathrm{m}}\right.$ and $\left.V_{\max }\right)$ of free and immobilized laccases through the applied dyes were also calculated.

\section{Materials and methods}

\section{Enzyme, chemicals and dyes}

The extracellular laccase of $P$. variabile, designated as $P v \mathrm{~L}$, was purified from the culture broth of cultivated fungus using the method described by Forootanfar et al. [8] and used as enzyme source in the present study. CPC-silica beads pre-silanized with 3-aminopropyltriethoxysilane (APTES), glutaraldehyde solution (25\%), and 2,2'azinobis-(3-ethylbenzothiazoline-6-sulfonate) (ABTS) were purchased from Sigma-Aldrich (St. Louis, MO, USA). 1-Hydroxybenzotriazole (HBT) was provided by Merck Chemicals (Darmstadt, Germany). Two synthetic dyes, Acid Blue 25 (AB25) and Acid Orange 7 (AO7)
(Table 1), were obtained from Alvan Sabet Co. (Tehran, Iran). All other reagents and chemicals were of the highest purity available.

\section{Laccase immobilization}

The $P v \mathrm{~L}$ was immobilized on the porous silica beads based on the method of Champagne and Ramsay [3]. Briefly, $4 \mathrm{~g}$ of pre-silanized CPC-silica beads (355-600 mm in diameter, an average surface area of $42.1 \mathrm{~m}^{2} / \mathrm{g}$, and a pore size of $37.5 \mathrm{~nm}$ ) was added to $2.5 \%$ glutaraldehyde solution (degassed under 2.0 bar vacuum pressure for $2 \mathrm{~h}$ ) in $0.1 \mathrm{M}$ $\mathrm{KH}_{2} \mathrm{PO}_{4}$ at pH 5.0 and stirred for $2 \mathrm{~h}$. The enzyme solution (prepared in citrate buffer $0.1 \mathrm{M}, \mathrm{pH} 5$ ) was then introduced to the activated silica beads and incubated at $4{ }^{\circ} \mathrm{C}$ for $36 \mathrm{~h}$. Consequently, the prepared beads was filtered through paper filter and washed three times with distilled water and twice with citrate buffer $(0.1 \mathrm{M}, \mathrm{pH} 5.0)$. The SEM image of CPC-silica beads and immobilized $P v \mathrm{~L}$ on porous silica beads were then recorded using a scanning electron microscope (Philips XL30) operated at $5 \mathrm{kV}$.

\section{Determination of thermal and $\mathrm{pH}$ stability of free and immobilized PVL}

Stability of the prepared immobilized $P v \mathrm{~L}$ and the free purified laccase through temperature was studied by pre-incubating the free or immobilized $P v \mathrm{~L}$ at different temperatures between 20 and $60^{\circ} \mathrm{C}$ for $1 \mathrm{~h}$, followed by determination of the residual activity. The influence of $\mathrm{pH}$ on the laccase stability was evaluated by incubating the free or immobilized $P v \mathrm{~L}$ at $4^{\circ} \mathrm{C}$ in different $\mathrm{pH}$ levels (3-8) for $24 \mathrm{~h}$ and determining the residual activity.

\section{Laccase activity determination}

The laccase activity was measured by oxidizing the ABTS as a substrate according to the method previously described $[17,18]$. Briefly, $0.5 \mathrm{~mL}$ of the purified $P v \mathrm{~L}$ solution or $0.1 \mathrm{~g}$ of immobilized $P v \mathrm{~L}$ was added to $1.5 \mathrm{~mL}$ of the ABTS solution $(5 \mathrm{mM}$ in citrate buffer $0.1 \mathrm{M}$, $\mathrm{pH} 5$ ) and incubated at $40^{\circ} \mathrm{C}$ and $120 \mathrm{rpm}$ for $10 \mathrm{~min}$. Change in the absorbance at $420 \mathrm{~nm}$ was then determined using a UV-vis spectrophotometer (UVD 2950, Labomed, Culver City, USA). The laccase activity was then calculated using the molar extinction coefficient of

Table 1 Chemical type, maximum absorbances, and kinetic parameters of two synthetic dyes

\begin{tabular}{|c|c|c|c|c|}
\hline Dye name & Type & $\lambda_{\max }(\mathrm{nm})$ & $K_{m}(\mathrm{mM})$ & $V_{\max }\left(\mathrm{mmol} \min ^{-1} \mathrm{mg}^{-1}\right)$ \\
\hline \multirow[t]{2}{*}{ Acid orange 7} & Azo & 485 & $2.75^{a}$ & $146^{a}$ \\
\hline & & & $2.25^{\mathrm{b}}$ & $225^{\mathrm{b}}$ \\
\hline \multirow[t]{2}{*}{ Acid blue 25} & $A Q^{c}$ & 600 & $1.23^{\mathrm{a}}$ & $165^{a}$ \\
\hline & & & $0.736^{b}$ & $254^{\mathrm{b}}$ \\
\hline
\end{tabular}

${ }^{a}$ Calculated $K_{m}$ and $V_{\text {max }}$ in presence of immobilized laccase.

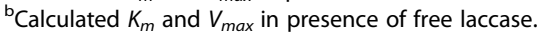

${ }^{c}$ Anthraquinone. 
$\operatorname{ABTS}\left(\varepsilon_{420}=36,000 \mathrm{M}^{-1} \mathrm{~cm}^{-1}\right)$. One unit enzyme activity was defined as the amount of enzyme requires oxidizing $1 \mu \mathrm{mol}$ of ABTS per minute under the assay condition [19].

\section{Dye decolorization experiments}

Decolorization experiments were performed by adding the free or immobilized $P v \mathrm{~L}$ (final activity of $2 \mathrm{U} / \mathrm{mL}$ ) to each dye solution (a concentration of $400 \mathrm{mg} / \mathrm{L}$ achieved from a preliminary study), which was previously prepared by dissolving each dye in a citrate-phosphate buffer (0.1 M, pH 5.0), followed by incubation of the reaction mixture (final volume of $2.5 \mathrm{~mL}$ ) at $40^{\circ} \mathrm{C}$ and $50 \mathrm{rpm}$ for $1 \mathrm{~h}$. Decolorization percentage was then determined by monitoring absorbance of the taken samples (each 5 min up to $1 \mathrm{~h}$ ), using a UV-vis spectrophotometer at the maximum absorbance of each dye (Table 1). Incubation of the reaction mixture was then continued overnight to confirm any significant change in decolorization percentage. The following equation was used to estimate the percentage of decolorization:

$$
\text { Decolorization }(\%)=\left[\mathrm{A}_{\mathrm{i}}-\mathrm{A}_{\mathrm{t}} / \mathrm{A}_{\mathrm{i}}\right] \times 100
$$

where $A_{i}$ is the initial absorbance of the reaction mixture and $A_{t}$ is the absorbance after incubation time [5,18]. In the case of free $P v \mathrm{~L}$, the negative control was prepared by adding the heat-inactivated enzyme to the dye solution and incubating the reaction mixture as described above. In the case of immobilized $P v \mathrm{~L}$, activated glass beads without enzyme applied as negative control. All experiments were performed in triplicate and means of decolorization percentages were reported.

\section{The effect of laccase activity on dye decolorization}

In order to determine the effect of laccase activity on decolorization pattern, the purified or immobilized $P v \mathrm{~L}$ was added to the reaction mixture (as said above) to reach the enzyme activity of $0.5-8 \mathrm{U} / \mathrm{mL}$ followed by incubation at $40^{\circ} \mathrm{C}$ and $50 \mathrm{rpm}$ for $60 \mathrm{~min}$. The reaction mixture was then monitored for decolorization percentage. The final dye concentration in all experiments was $400 \mathrm{mg} / \mathrm{L}$.

\section{The influence of $\mathrm{pH}$ on laccase-mediated decolorization}

By adjusting the initial $\mathrm{pH}$ of each dye solution (final concentration of $400 \mathrm{mg} / \mathrm{L}$ ) using $0.1 \mathrm{M}$ citrate-phosphate buffer between $3-8,2 \mathrm{U} / \mathrm{mL}$ free or immobilized $P v \mathrm{~L}$ was added to the reaction mixture and incubated at $40^{\circ} \mathrm{C}$ and $50 \mathrm{rpm}$ for $60 \mathrm{~min}$. The decolorization percentage was then monitored as previously described.

\section{The effect of temperature on enzymatic decolorization} The effect of temperature on enzymatic decolorization was studied by incubating $400 \mathrm{mg} / \mathrm{L}$ of the synthetic dyes in the presence of $2 \mathrm{U} / \mathrm{mL}$ of free or immobilized $\mathrm{P} \nu \mathrm{L}$ at temperature range of $25-70^{\circ} \mathrm{C}$ and $\mathrm{pH} 5$.

\section{Application of laccase-HBT mediated system for dye decolorization}

HBT as a non-phenolic laccase mediator was introduced to the reaction mixture (dye, $400 \mathrm{mg} / \mathrm{L}$ and free or immobilized $P v \mathrm{~L}, 2 \mathrm{U} / \mathrm{mL}$ in citrate buffer $0.1 \mathrm{M} \mathrm{pH} 5$ ) to reach the final concentrations of $0.1,1$, and $5 \mathrm{mM}$. Decolorization was determined as previously described.

\section{Reusability of immobilized laccase}

In order to determine the reusability of immobilized biocatalyst, the applied immobilized $P v \mathrm{~L}$ was recovered from the reaction mixture of each dye using filtration and washed three times with citrate buffer $(0.1 \mathrm{M}$, $\mathrm{pH} 5$ ). It was then introduced again to the reaction mixture and residual activity of the immobilized $P v \mathrm{~L}$ was measured as said above. The mentioned experiment was done in triplicate and mean of obtained results were reported.

\section{Kinetic studies}

After determination of velocity in presence of different concentrations $(100-600 \mathrm{mg} / \mathrm{L})$ of each dye, the Michaelis - Menten curve was drawn by plotting the obtained velocity (V) against the dye concentrations (S). The kinetic parameters $\left[K_{\mathrm{m}}\right.$ (Michaelis constant) and $V_{\text {max }}$ (maximal velocity)] of the free or immobilized $P v L$ through each dye were then obtained using the Lineweaver-Burk transformation of the Michaelis-Menten equation.

\section{Statistical analysis}

All above mentioned experiments performed in triplicate and the reported data were presented as mean \pm standard deviation. The independent sample $t$-test and oneway analysis of variance (ANOVA) with Dunnett's T3 post Hoc test was done using the SPSS 15 software (SPSS Inc) to calculate statistical significance between mean values. Probability values $<0.05$ were considered to be significant.

\section{Results and discussion}

\section{Immobilization of laccase}

Figure 1a and Figure 1b represented the SEM images of CPC-silica beads and immobilized laccase on porous silica beads, respectively. Well dispersed particles without aggregation were formed after $P v \mathrm{~L}$ attachment (Figure 1b). It can be seen that smooth and spherical shape silica beads (Figure 1a) changed to rough and asymmetric particles after loading $P \nu \mathrm{L}$ on silica beads (Figure 1b). Similar observation was reported by Sadighi and Faramarzi [18] after loading the laccase on chitosan 


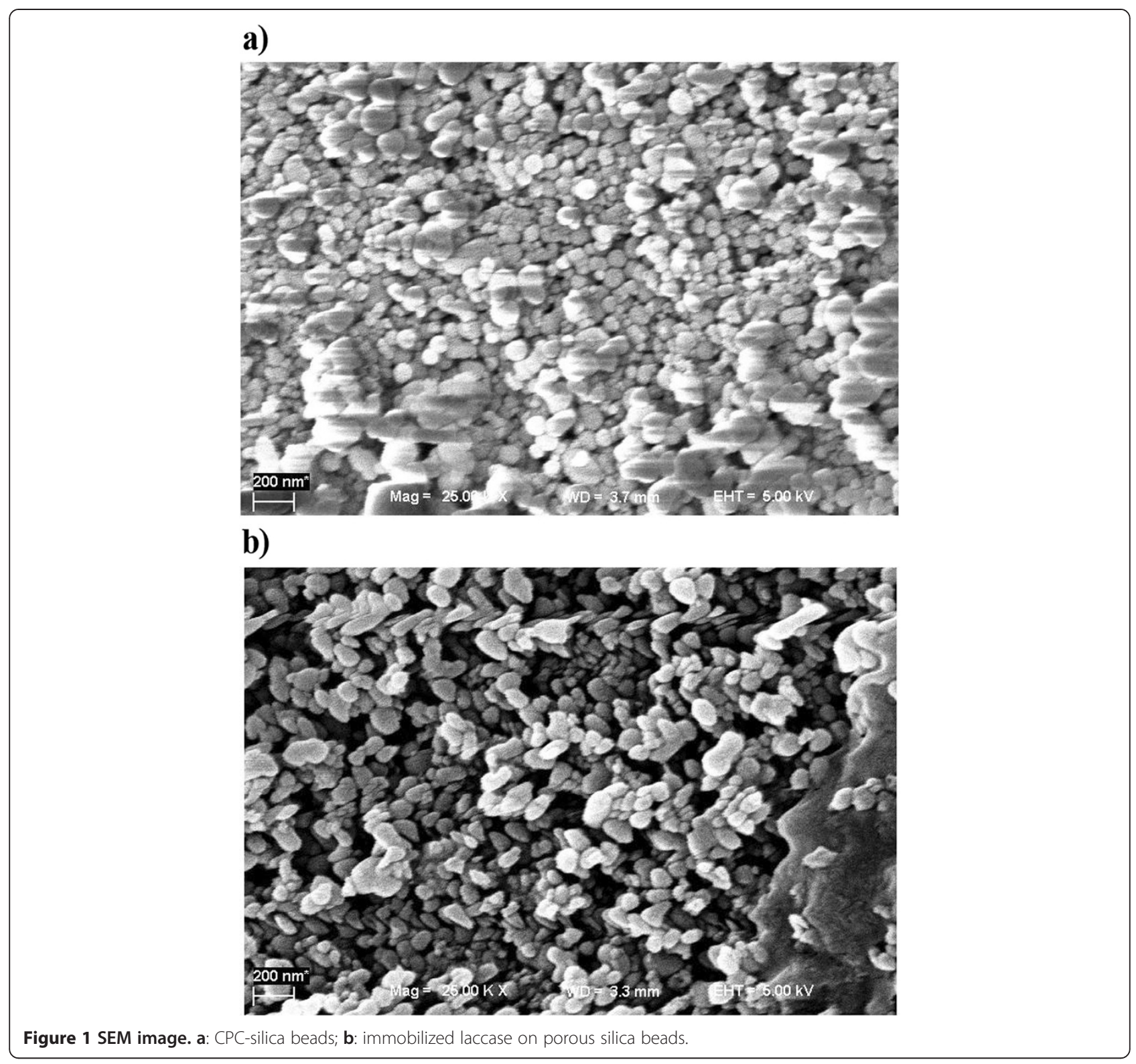

nanoparticles. The enzymatic attachment was there introduced as the probable reason for such morphological modification. The nitrogen adsorption-desorption isotherm data before incorporation of the enzyme indicated that the surface area of silica is about $40 \pm 5 \mathrm{~m}^{2} / \mathrm{g}$ (data not shown). Temperature and $\mathrm{pH}$ stability curve of the immobilized laccase compared to free enzyme are illustrated in Figure $2 \mathrm{a}$ and Figure $2 \mathrm{~b}$, respectively. At elevated temperature of $60^{\circ} \mathrm{C}$ the immobilized laccase showed $84 \%$ relative activity where only $4.6 \%$ initial activity of the free $P v \mathrm{~L}$ was remained at this temperature (Figure 2a). pH stability of the immobilized $P v \mathrm{~L}$ exhibited a broader range of activity in comparison with free laccase (Figure 2b).
Compare to free enzymes, immobilization of biocatalysts on solid supports made them more stable for industrial processes and allow them to be reused many times $[14,20]$. The obtained results of the present study revealed that immobilized laccase on porous silica beads represented higher temperature and $\mathrm{pH}$ stability compared to the free laccase. Same results were reported by Arica et al. [21] and Bayramoglu et al. [22] where the purified laccase of Trametes versicolor was immobilized on poly(GMA/EGDMA) and epoxy-functionalized magnetic chitosan beads, respectively. In the study of Wang et al. [23], it was revealed that immobilization of laccase on magnetic mesoporous silica particles enhanced the optimum catalytic temperature and $\mathrm{pH}$ of the enzyme 

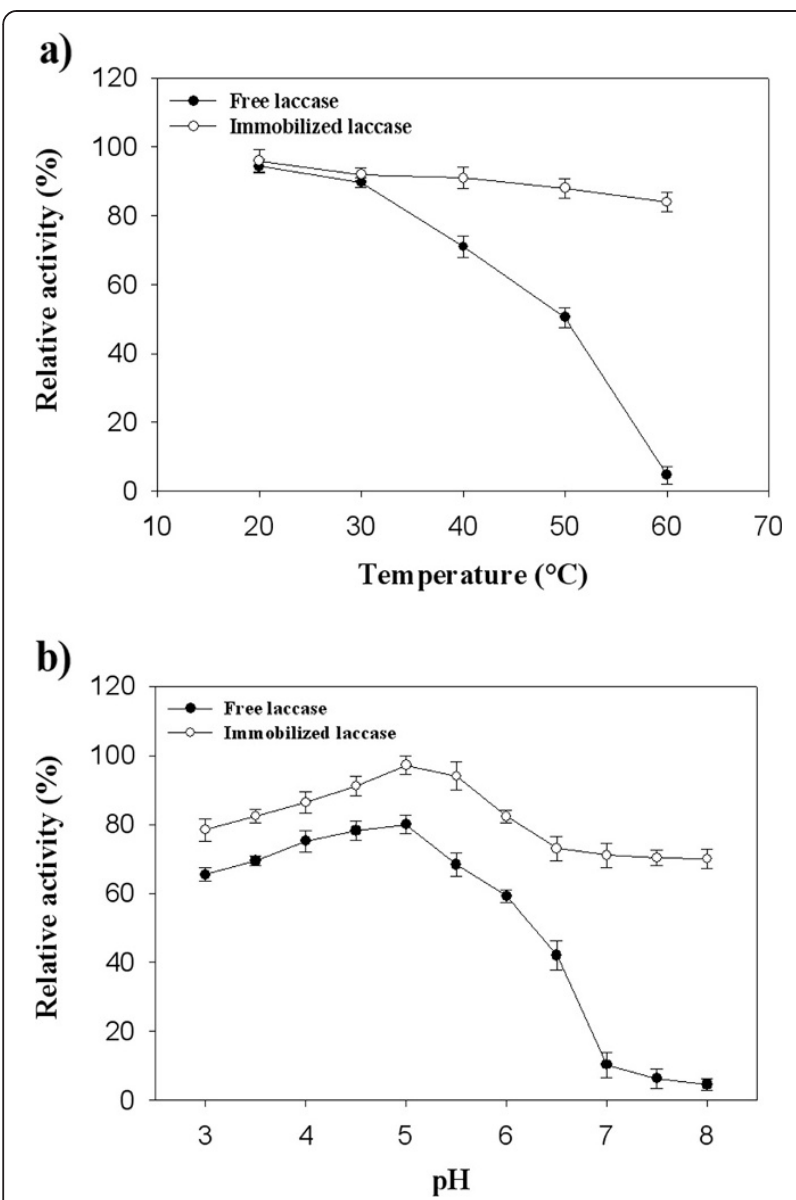

Figure 2 Stability of the immobilized laccase. a: Temperature stability; $\mathbf{b}$ : pH stability.

from $20^{\circ} \mathrm{C}$ and $\mathrm{pH} 4$ to $60^{\circ} \mathrm{C}$ and $\mathrm{pH} 5$, respectively. Meanwhile, they showed that the immobilized laccase exhibited more than $95 \%$ of the maximum activity with a wider $\mathrm{pH}$ range between 4.0 and 5.5 [23].

\section{Decolorization using free and immobilized laccase}

As shown in Figure $3 \mathrm{a}$, the free $P v \mathrm{~L}(2 \mathrm{U} / \mathrm{mL})$ was able to decolorize $39 \%$ of $\mathrm{AB} 25$ and $35 \%$ of $\mathrm{AO} 7$ after $65 \mathrm{~min}$ incubation while the immobilized enzyme removed $76 \%$ and $64 \% \mathrm{AB} 25$ and AO7, respectively at the same time (Figure $3 \mathrm{~b}$ ). Further incubation of the reaction mixtures for $24 \mathrm{~h}$ did not show any significant increase in decolorization percentages (data not shown). In decolorization experiments, the chemical structure of applied dyes is one of the most important factors affects on decolorization percentage $[1,24,25]$. In general, azo dyes were found to be resistant to laccase-mediated decolorization while anthraquinone dyes are suitable substrate for laccases [1,4]. The obtained results of the present study showed higher decolorization percent for the anthraquinone dye of AB25 compare to azo dye of AO7 using both the free and immobilized laccases. In the study of Ashrafi et al. [26], where the free $P \nu L$ was applied for decolorization of thirteen synthetic dyes, the lowest decolorization percentage was achieved for Direct Blue 71 (a triazo dye) and Reactive Red 120 (a diazo dye) after $180 \mathrm{~min}$ incubation at $40^{\circ} \mathrm{C}$.

\section{Effect of laccase activity on decolorization}

Effect of increasing laccase concentration on decolorization of studied dyes was illustrated in Figure 3c and Figure $3 \mathrm{~d}$. In the case of free $P v \mathrm{~L}$, the highest decolorization percent $(52.2 \%$ for AB25 and $46.2 \%$ for AO7) was achieved at laccase activity of $4 \mathrm{U} / \mathrm{mL}$ (Figure 3c) while in the case of immobilized laccase maximum decolorization percent $(75 \%$ for $\mathrm{AB} 25$ and $62 \%$ for $\mathrm{AO} 7$ ) was obtained in presence of $2 \mathrm{U} / \mathrm{mL}$ of laccase (Figure 3d). Depends on the sources of laccases (bacteria, fungi, etc.) decolorization pattern even on one special dye has been found to be different [4,27]. In our previous studies $[4,7-10,18]$, the produced laccase of $P$. varibile was efficiently decolorized wide range of synthetic dyes including diazo dyes (Amido black, Sudan black, Congo red and Ponceau-S), triphenylmethane dyes (Crystal violet, Bromothymol blue, Commassie brilliant blue and Malachite green) and anthraquinone dyes (Rimazol brilliant blue R). The recent study of Ashrafi et al. [26] showed that increasing of laccase concentration from 0.025 to $0.1 \mathrm{U} / \mathrm{mL}$ significantly increased decolorization percent in all thirteen studied synthetic dyes.

\section{Influence of $\mathrm{pH}$ on decolorization}

As represented in Figure 4a and Figure 4b the maximum decolorization in the case of both applied dyes and using free and immobilized laccases was occurred at optimum $\mathrm{pH}$ of $P v \mathrm{~L}(\mathrm{pH}$ 5). Relative decolorization of free $P v \mathrm{~L}$ at $\mathrm{pH} 6$ decreased by 35\% and 31\% in the case of $\mathrm{AB} 25$ and AO7, respectively (Figure 4a) while only 4\% (AO7) and $1.5 \%$ (AB25) of maximum decolorization was lost in the case of immobilized laccase at $\mathrm{pH} 6$ (Figure 4b). In comparison with the free laccase, the immobilized laccase exhibited more than $80 \%$ of the maximum decolorization with a wider $\mathrm{pH}$ range between 4.5 and 6 (Figure 4b).

\section{Effect of temperature on laccase decolorization}

As shown in Figure $4 \mathrm{c}$ and Figure $4 \mathrm{~d}$ the highest decolorization percent in the case of both synthetic dyes was obtained at optimum temperature of $P v \mathrm{~L}$ activity $\left(40^{\circ} \mathrm{C}\right)$. At elevated temperature of $70^{\circ} \mathrm{C}$, relative decolorization of both dyes was decreased below $20 \%$. However, in the case of immobilized $P v \mathrm{~L}$ above $75 \%$ of initial decolorization remained at temperature of $70^{\circ} \mathrm{C}$ (Figure 4d). In the study of Sadighi et al. [18] it was found that the laccase immobilized on chitosan 
a)

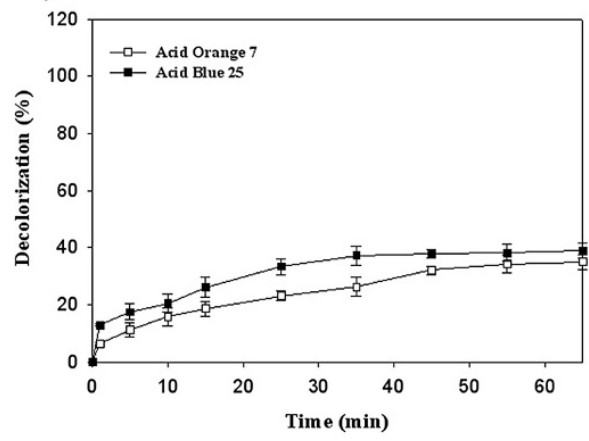

c)

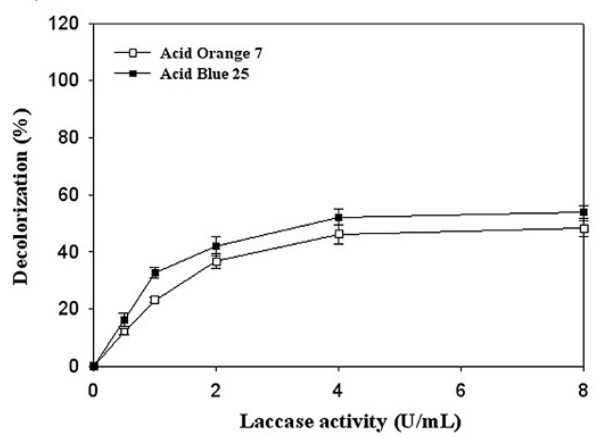

b)

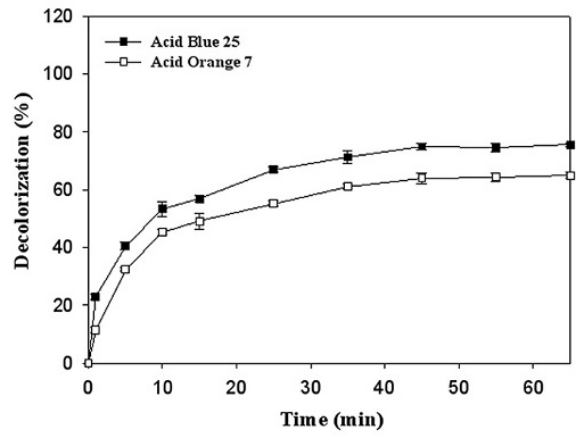

d)

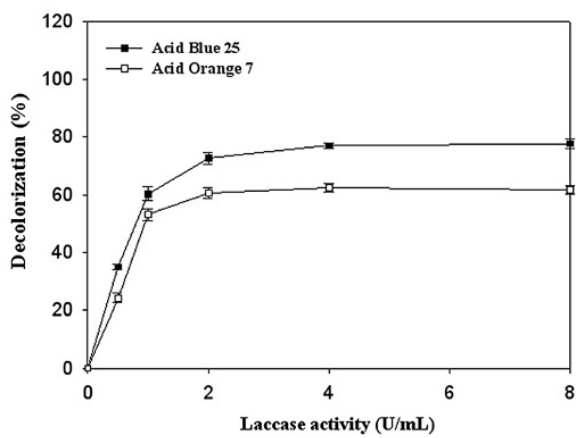

Figure $\mathbf{3}$ Time course study and the influence of laccase activity on dye decolorization. $\mathbf{a}$ and $\mathbf{c}$ : free laccase; $\mathbf{b}$ and $\mathbf{d}$ : immobilized laccase.

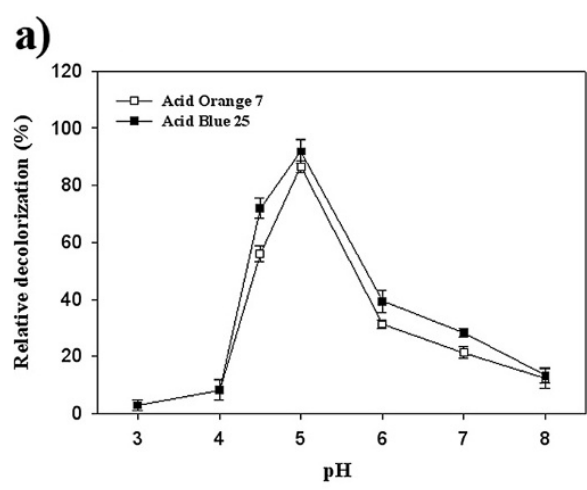

c)

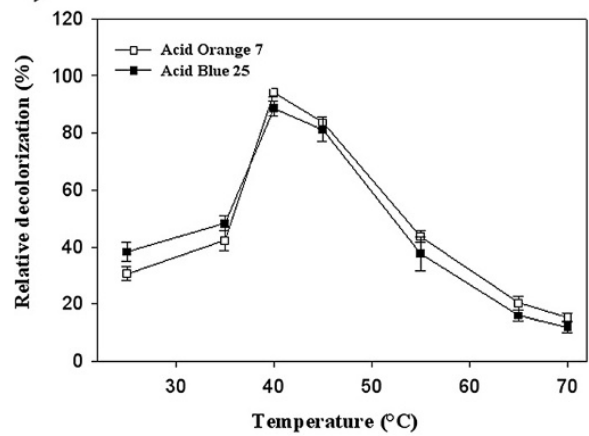

b)

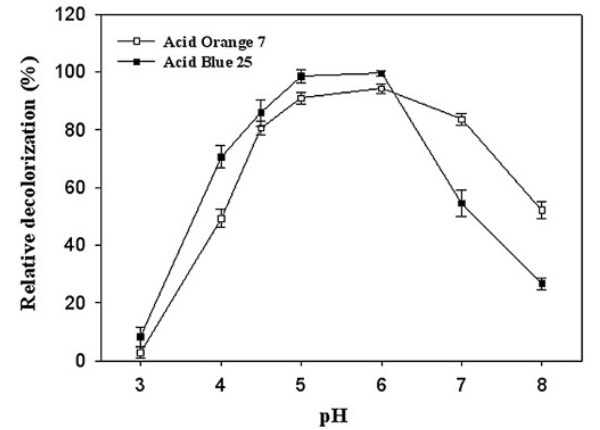

d)

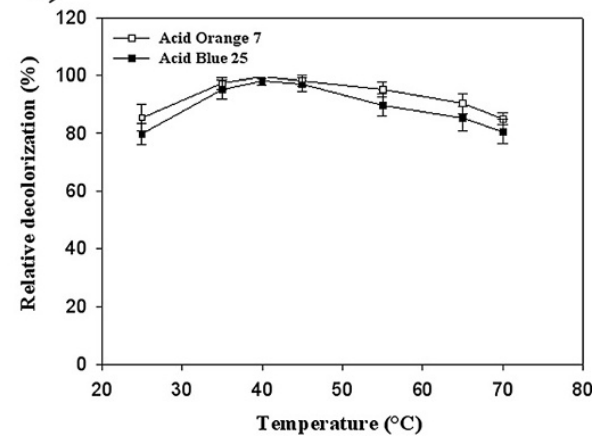

Figure 4 Effects of $\mathrm{pH}$ and temperature on dye decolorization after $65 \mathrm{~min}$ incubation. $\mathbf{a}$ and $\mathbf{c}$ : free laccase, $\mathbf{b}$ and $\mathbf{d}$ : immobilized laccase. 
nanoparticles retained decolorization activity of Congo red at $95^{\circ} \mathrm{C}$, and eventually lost $66 \%$ of decolorization activity at $100^{\circ} \mathrm{C}$

\section{Effect of HBT on laccase-mediated decolorization}

Results of decolorization experiments using free and immobilized $P v \mathrm{~L}$ in absence and presence of HBT as laccase mediator are illustrated in Figure 5. In the case of free laccase, increasing of HBT concentration from 0.1 to $1 \mathrm{mM}$ enhanced decolorization percent of both investigated dyes (Figure 5a). However, in the case of immobilized $P v \mathrm{~L}$, higher concentration of HBT (above $5 \mathrm{mM}$ ) decreased decolorization percent (Figure 5b). Sadighi et al. [18] determined higher relative decolorization in presence of HBT $(0.5 \mathrm{mM})$ using laccase immobilized on chitosan nanoparticles. Laccase-HBT system is one of the most successful laccase-mediated systems used for removal of pollutants, elimination of some synthetic dyes [5] and degradation of some pharmaceutical agents

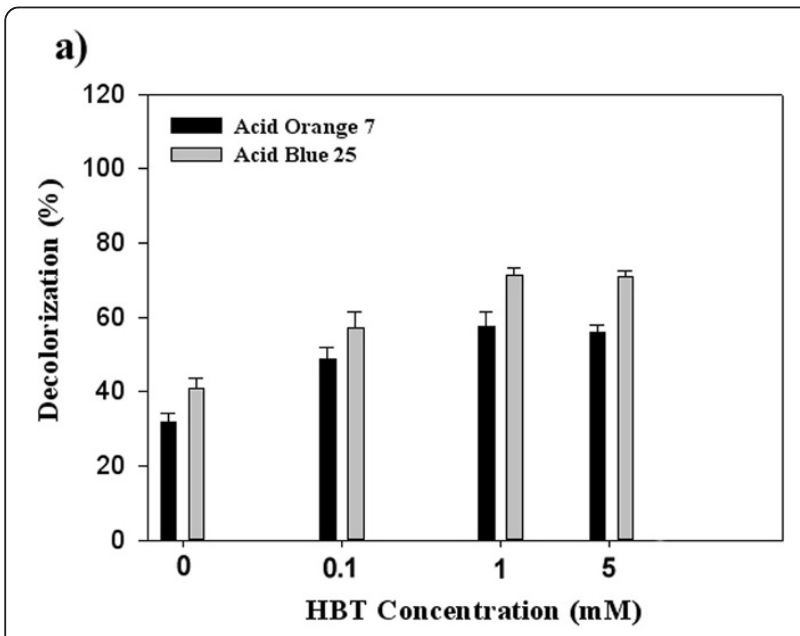

b)

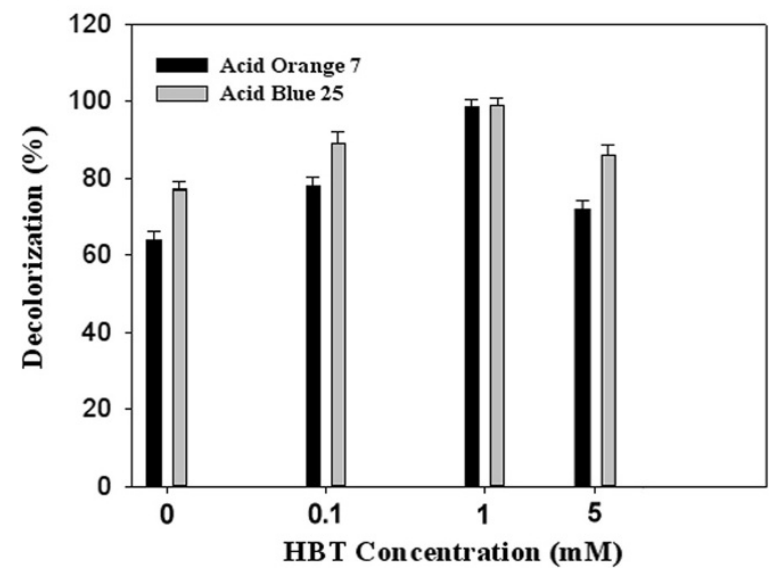

Figure 5 Application of laccase-HBT system at a concentration of $\mathbf{0 . 1}, \mathbf{1}$, and $5 \mathrm{mM}$ for dye decolorization. a: free laccase; b: immobilized laccase.
[19]. However, the mediating activity of HBT was found to be proportional due to the destructive effect of the $\mathrm{N}-\mathrm{O}$. group on the laccase activity, especially at a high concentration [28]. For example, decolorization percent of the triazo dye (Direct blue 71) was increased from 50\% (unaided laccase) to $86 \%$ (in the presence HBT, $5 \mathrm{mM}$ ) using the free $P v \mathrm{~L}$ while inverse effect, decreasing decolorization percent from $97 \%$ (laccase alone) to $69.4 \%$ (laccase-HBT at a concentration of $5 \mathrm{mM}$ ), was observed in the case of Reactive Red 120 (a monoazo dye) [26].

\section{Reusability of immobilized laccase}

The reusability of prepared immobilized enzymes is one of the most important factors for reducing overall cost of industrially applied enzymes $[18,29,30]$. The profile of decrease in relative decolorization of immobilized laccase during nine cycles of usage in our study is presented in Figure 6. Only 26\% and 31\% initial activity of the immobilized $P v \mathrm{~L}$ lost after nine cycles of application in the case of AB25 and AO7, respectively. The results of our previous study revealed that relative decolorization of $P$. variabile laccase immobilized on alginategelatin mixture fallen to $20 \%$ when applied seven times in decolorization experiments [7]. However, study of Sadighi et al. [18] showed that $96 \%$ of biocatalytic (the laccase from Aspergillus oryzae, Denilite IIS, immobilized on glass beads) activity was still retained after 25 reusing rounds of Congo red decolorization. About $60 \%$ initial activity of the immobilized laccase of Pleurotus sajor-caju on functionalized SBA-15 mesoporous silica was remained after fourteen reaction cycles [11].

\section{Kinetic parameters of free and immobilized laccases}

Kinetic parameters of free and immobilized laccases toward two studied dyes of AB25 and AO7 were summarized in Table 1 . Since anthraquinoid dyes especially

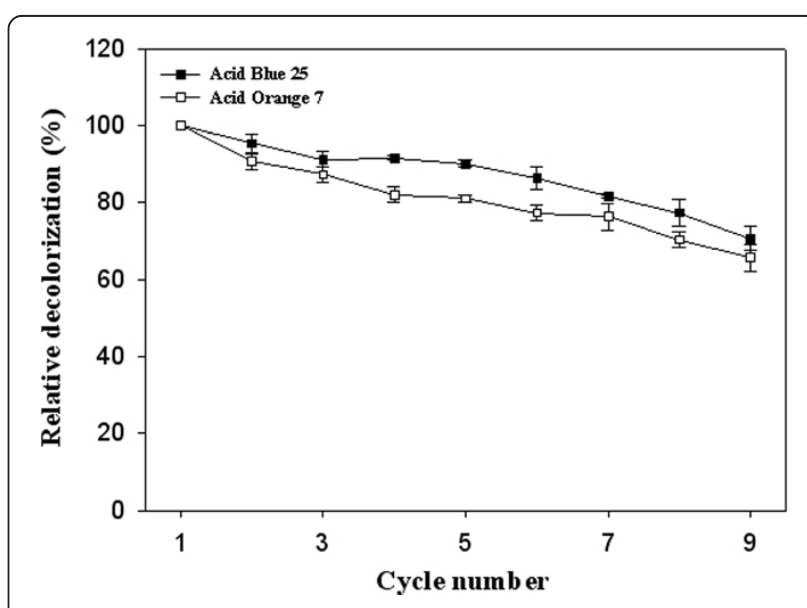

Figure 6 Reusability potential of immobilized PvL after 7 cycles of decolorization. Data are presented as mean $\pm S D(n=3)$. 
those with amine groups on the ring are more suitable substrates than azo dyes for laccase [31], $K_{m}$ value of both free and immobilized laccases for AB25 is lower than $\mathrm{AO} 7$ and also the degradation of $\mathrm{AB} 25$ is faster than $\mathrm{AO} 7$, i.e., the $V_{\max }$ for $\mathrm{AB} 25$ is higher than AO7. On the other hand, the higher $K_{m}$ value of immobilized $P v \mathrm{~L}$ toward both applied dyes means lower affinity of immobilized laccase for applied dyes compared to free laccase. The obtained results are in agreement with the results achieved by Rekuc et al. [32] indicating 3.4 fold increase in $K_{m}$ value of immobilized laccase compared to free laccase. Such observation might be due to structural change in the adsorption process of laccase onto solid support and low accessibility of the substrate to the active site of the immobilized laccase [23,33].

\section{Conclusion}

The purified laccase of $P$. variabile, recently studied for its capacity in the removal of aromatic compounds (e.g., chlorophenol pollutants, hazardous synthetic dyes, and pharmaceutical agents), was immobilized on porous silica beads and applied for decolorization of two synthetic dyes of Acid Blue 25 (an anthraquinone dye) and Acid Orange 7 (an azo dye). pH and thermal stability of immobilized enzyme was improved compare to free laccase. Both applied dyes were efficiently decolorized using immobilized laccase. Application of the laccase-HBT system improved the decolorization of both synthetic dyes using free and immobilized laccases.

\section{Competing interests}

The authors declare that they have no competing interests.

\section{Authors' contributions}

SSM carried out decolorization studies. Production and purification of laccase from $P$. variabile culture broth was performed by HF. SMK participated in decolorization studies and writing of the manuscript. SR participated in the studies of decolorization kinetic. AHM contributed in writing of the manuscript, decolorization studies and analyzing of data. MAF involved in purchasing of required materials and instruments, designing of decolorization experiments, analyzing of data and reviewing of the manuscript. All authors read and approved the final manuscript.

\section{Acknowledgement}

This work was financially supported by the Biotechnology Research Center, Tehran University of Medical Sciences, Tehran, Iran and Institute for Environmental Research, Tehran University of Medical Sciences.

\footnotetext{
Author details

'Department of Pharmaceutical Biotechnology, Faculty of Pharmacy and Biotechnology Research Center, Tehran University of Medical Sciences, Tehran 14176, Iran. 'Department of Environmental Health Engineering, School of Public Health; Center for Solid Waste Research; Institute of Public Health Research, Tehran University of Medical Sciences, Tehran, Iran. ${ }^{3}$ Department of Environmental Engineering, West Tehran Branch Islamic Azad University, Tehran, Iran. ${ }^{4}$ Environment and Energy Department, Science and Research Branch, Islamic Azad University, Tehran, Iran. ${ }^{5}$ Department of Pharmaceutical Biotechnology, Faculty of Pharmacy, Kerman University of Medical Sciences, Kerman, Iran. ${ }^{6}$ Center for Water Quality Research, Institute for Environmental Research, Tehran University of Medical sciences, Tehran, Iran.
}

Received: 20 June 2013 Accepted: 6 October 2013

Published: 6 January 2014

\section{References}

1. Saratale RG, Saratale GD, Chang JS, Govindwar SP: Bacterial decolorization and degradation of azo dyes: a review. J Taiwan Inst Chem Eng 2011, 42:138-157.

2. Cristovao RO, Tavares APM, Brigida Al, Loureiro JM, Boaventura RAR, Macedo EA, Coelho MAZ: Immobilization of commercial laccase onto green coconut fiber by adsorption and its application for reactive textile dyes degradation. J Mol Catal B 2011, 72:6-12.

3. Champagne PP, Ramsay JA: Dye decolorization and detoxification by laccase immobilized on porous glass beads. Bioresour Technol 2010, 101:2230-2235.

4. Forootanfar $\mathrm{H}$, Moezzi A, Aghaie-Khouzani M, Mahmoudjanlou Y, Ameri A, Niknejad F, Faramarzi MA: Synthetic dye decolorization by three sources of fungal laccase. J Environ Health Sci Eng 2012, 9:27.

5. Khlifi R, Belbahri L, Woodward S, Ellouz M, Dhouib A, Sayadi S, Mechichi T: Decolourization and detoxification of textile industry wastewater by the laccase-mediator system. J Hazard Mater 2010, 175:802-808.

6. Vinoth Kumar V, Prem Kumar MP, Thiruvenkadaravi KV, Baskaralingam P, Senthil Kumar P, Sivanesan S: Preparation and characterization of porous cross linked laccase aggregates for the decolorization of triphenyl methane and reactive dyes. Bioresour Technol 2012, 119:28-34.

7. Mogharabi M, Nassiri-Koopaei N, Bozorgi-Koushalshahi M, Nafissi-Varcheh N, Bagherzadeh G, Faramarzi MA: Immobilization of laccase in alginategelatin mixed gel and decolorization of synthetic dyes. Bioinorg Chem App/ 2012, 823830:6.

8. Forootanfar H, Faramarzi MA, Shahverdi AR, Tabatabaei Yazdi M: Purification and biochemical characterization of extracellular laccase from the ascomycete Paraconiothyrium variabile. Bioresour Technol 2011, 102:1808-1814.

9. Aghaie-Khouzani M, Forootanfar H, Moshfegh M, Khoshayand MR, Faramarzi MA: Decolorization of some synthetic dyes using optimized culture broth of laccase producing ascomycete Paraconiothyrium variabile. Biochem Eng J 2012, 60:9-15.

10. Forootanfar H, Movahednia MM, Yaghmaei S, Tabatabaei-Sameni M, Rastegar H, Sadighi A, Faramarzi MA: Removal of chlorophenolic derivatives by soil isolated ascomycete of Paraconiothyrium variabile and studying the role of its extracellular laccase. J Hazard Mater 2012, 209-210:199-203.

11. Salis A, Pisano M, Monduzzi M, Solinas V, Enrico Sanjust E: Laccase from Pleurotus sajor-caju on functionalised SBA-15 mesoporous silica: Immobilisation and use for the oxidation of phenolic compounds. J Mol Catal B 2009, 58:175-180.

12. Ping W, Xuerong F, Li C, Qiang W, Aihui Z: Decolorization of reactive dyes by laccase immobilized in alginate/gelatin blent with PEG. J Environ Sci 2008, 20:1519-1522

13. Forde J, Tully E, Vakurov A, Gibson TD, Millner P, Ofagain C: Chemical modification and immobilisation of laccase from Trametes hirsuta and from Myceliophthora thermophila. Enzyme Microb Technol 2010, 46:430-437.

14. Fernandez-Fernandez M, Sanroman MA, Moldes D: Recent developments and applications of immobilized laccase. Biotechnol Adv 2012. doi:10.1016/ j.biotechadv.2012.02.013.

15. Yemul O, Imae T: Covalent-bonded immobilization of lipase on poly (phenylene sulfide) dendrimers and their hydrolysis ability. Biomacromolecules 2005, 6:2809-2814.

16. Bautista LF, Morales G, Sanz R: Immobilization strategies for laccase from Trametes versicolor on mesostructured silica materials and the application to the degradation of naphthalene. Bioresour Technol 2010 101:8541-8548.

17. Faramarzi MA, Forootanfar $\mathrm{H}$ : Biosynthesis and characterization of gold nanoparticles produced by laccase from Paraconiothyrium variabile. Colloids Surf B 2011, 87:23-27.

18. Sadighi A, Faramarzi MA: Congo red decolorization by immobilized laccase through chitosan nanoparticles on the glass beads. J Taiwan Inst Chem Eng 2013, 44:156-162.

19. Ostadhadi-Dehkordi S, Tabatabaei-Sameni M, Forootanfar H, Kolahdouz S, Ghazi-Khansari M, Faramarzi MA: Degradation of some benzodiazepines by a laccase-mediated system in aqueous solution. Bioresour Technol 2012, 125:344-347.

20. Gholami-Borujeni F, Mahvi AH, Naseri S, Faramarzi MA, Nabizadeh R, Alimohammadi M: Application of immobilized horseradish peroxidase for removal and detoxification of azo dye from aqueous solution. Res I Chem Environ 2011, 15:217-222. 
21. Arica MY, Altıntas B, Bayramoglu G: Immobilization of laccase onto spacer-arm attached non-porous poly(GMA/EGDMA) beads: application for textile dye degradation. Bioresour Technol 2009, 100:665-669.

22. Bayramoglu G, Yilmaz M, Arica MY: Preparation and characterization of epoxyfunctionalized magnetic chitosan beads: laccase immobilized for degradation of reactive dyes. Bioprocess Biosyst Eng 2010, 33:439-48.

23. Wang F, Guo C, Yang L-R, Liu C-Z: Magnetic mesoporous silica nanoparticles: fabrication and their laccase immobilization performance. Bioresour Technol 2010, 101:8931-8935.

24. Gholami-Borujeni F, Mahvi AH, Nasseri S, Faramarzi MA, Nabizadeh R, Alimohammadi M: Enzymatic treatment and detoxification of acid orange 7 from textile wastewater. Appl Biochem Biotechnol 2011, 165:1274-1284.

25. Gholami-Borujeni F, Faramarzi MA, Nejatzadeh-Barandozi F, Mahvi AH: Oxidative degradation and detoxification of textile azo dye by horseradish peroxidase enzyme. Fresen Environ Bull 2013, 22:739-744.

26. Ashrafi SD, Rezaei S, Forootanfar H, Mahvi AH, Faramarzi MA: The enzymatic decolorization and detoxification of synthetic dyes by the laccase from a soil-isolated ascomycete, Paraconiothyrium variabile. Int Biodeter Biodegr 2013, 85:173-181.

27. Zhuo R, Ma L, Fan F, Gong Y, Wan X, Jiang M, Zhang X, Yang Y; Decolorization of different dyes by a newly isolated white-rot fungi strain Ganoderma sp. En3 and cloning and functional analysis of its laccase gene. J Hazard Mater 2011, 192:855-873.

28. Papinutti L, Dimitriu P, Forchiassin F: Stabilization studies of Fomes sclerodermeus laccases. Bioresour Technol 2008, 99:419-424.

29. Kunamneni A, Ghazi I, Camarero S, Ballesteros A, Plou FJ, Alcalde M: Decolorization of synthetic dyes by laccase immobilized on epoxyactivated carriers. Process Biochem 2008, 43:169-178.

30. Faramarzi MA, Sadighi A: Insights into biogenic and chemical production of inorganic nanomaterials and nanostructures. Adv Coll Interface Sci 2013, 189-190:1-20.

31. Abadulla E, Tzanov T, Costa S, Robra KH, Cavaco-Paulo A, Gubitz1 GM: Decolorization and detoxification of textile dyes with a laccase from Trametes hirsute. Appl Environ Microbiol 2000, 66:3357-3362.

32. Rekuc A, Bryjak J, Szymanska K, Jarzebski AB: Laccase immobilization on mesostructured cellular foams affords preparations with ultra high activity. Process Biochem 2009, 44:191-198.

33. Dehghanifard E, Jafari AJ, Kalantary RR, Mahvi AH, Faramarzi MA, Esrafili A: Biodegradation of 2,4-dinitrophenol with laccase immobilized on nano-porous silica beads. J Environ Health Sci Eng 2013, 10:25.

doi:10.1186/2052-336X-12-6

Cite this article as: Mirzadeh et al: Decolorization of two synthetic dyes using the purified laccase of Paraconiothyrium variabile immobilized on porous silica beads. Journal of Environmental Health Science \& Engineering 2014 12:6.

\section{Submit your next manuscript to BioMed Central and take full advantage of:}

- Convenient online submission

- Thorough peer review

- No space constraints or color figure charges

- Immediate publication on acceptance

- Inclusion in PubMed, CAS, Scopus and Google Scholar

- Research which is freely available for redistribution 